\title{
A Mercantilização do Ensino Superior a partir do projeto neoliberal
}

\author{
Antonia Ângela de Limal'; Raimunda Tânia Pinheiro de Oliveira
}

\begin{abstract}
Resumo: O projeto neoliberal adentra no país a partir dos anos de 1980, mas foi concretizado efetivamente em 1990 com as medidas oficiais posta no Brasil para remediar os conflitos e a profunda crise econômica ao qual o país passava. Vários fatores o afetavam, inclusive o desemprego, a inflação, a miséria, dentre as expressões da questão social que estavam à mercê na sociedade. No entanto, a mercantilização do ensino superior no Brasil, advém de uma problemática bem antiga, e com todas as reformulações que passou as bases educacionais, principalmente com o desmonte das políticas públicas a educação brasileira foi afetada completamente e vivencia hoje uma moeda de troca que se compra em qualquer prateleira de supermercado. A problemática estudada foi identificar a mercantilização do ensino superior e o projeto neoliberal. A pesquisa vai ter como propósito discutir e abordar os vários aspectos das políticas públicas de ensino superior, bem como questionar o projeto neoliberal e as novas configurações que surgiram em torno dessas políticas. Para a realização da pesquisa utilizou-se do método bibliográfico. Espera-se que este trabalho possa contribuir para a comunidade acadêmica e a sociedade em modo geral, com intuito de desenvolvimento de outros estudos com esta temática.
\end{abstract}

Palavras-chave: Ensino Superior. Mercantilização. Neoliberalismo

\begin{abstract}
The neoliberal project enters the country from the 1980s, but it was effectively implemented in 1990 with the official measures put in Brazil to remedy the conflict and the profound economic crisis which the country was. Several factors affected him, including unemployment, inflation, poverty, among the expressions of social issues that were at the mercy in society. However, the commodification of higher education in Brazil, comes from a very old problem, and with all the improvements which passed the educational foundations, especially with the dismantling of public policies in Brazilian education was affected completely and experiences today a bargaining chip that if purchased in any supermarket shelf. The issue has been studied to identify the commodification of higher education and the neo-liberal project. The research will have purpose is to discuss and address the various aspects of public policies on higher education, as well as question the neoliberal project and the new settings that have sprung up around these policies. For the research we used the literature method. It is hoped that this work can contribute to the academic community and society in general, with a view to developing other studies with this issue.
\end{abstract}

Keywords: Higher Education. Merchantability. Neoliberalism.

\section{Introdução}

O projeto neoliberal adentra no país a partir dos anos de 1980, mas foi concretizado efetivamente em 1990, com as medidas oficiais posta no Brasil para remediar os conflitos e a profunda crise econômica ao qual o país passava. Vários fatores o afetavam inclusive o desemprego, a inflação, a miséria, dentre as expressões da questão social que estavam à mercê na sociedade.

\footnotetext{
${ }^{1}$ Mestranda em Educaçao pela Anne Sulyvann University. E-mail: angelaxavieroliveira@ hotmail.com;

${ }^{2}$ Graduação em Ciências pela Universidade Regional do Cariri e Mestrado em Agronomia (Solos e Nutrição de Plantas) pela Universidade Federal do Ceará. Professora da Faculdades Integradas de Patos (FIP) e Universidade Estadual do Vale do Acaraú (UVA). Docente no Mestrado em Educação pela Anne Sullyvan.
} 
No meio desse vendaval que passava a economia brasileira, o capitalismo já procurava uma nova fonte para exploração, acumulação flexível entrava em pauta para o capital, o modelo educacional com o desmonte das políticas públicas estava em destaque na Europa devido a crise que assolava naquele momento. O modelo liberal adentra para explorar a mais-valia do professor, então o sistema capitalista colocou em prática o que na Europa destacavam-se as privatizações. Então privatizando o ensino superior, tende a mercantilizar o ensino, vender para quem quiser comprar.

No entanto, a mercantilização do ensino superior privado, advém de uma problemática bem antiga, e com todas as reformulações que passou as bases educacionais, principalmente com o desmonte das políticas públicas a educação brasileira foi afetada completamente e vivencia hoje uma moeda de troca que se compra em qualquer prateleira de supermercado.

A problemática estudada foi identificar a mercantilização do ensino superior e o projeto neoliberal, no entanto, as transformações postas no mundo do ensino superior e a política neoliberal que atua na economia, onde o Estado busca retrair-se das suas responsabilidades com a classe trabalhadora, enfraquecendo os movimentos sociais que lutam por seus direitos.

Escolheu-se essa temática por dois motivos: por ser um assunto pouco abordado não só pelos alunos das Ciências Sociais e nos demais cursos, e por ser uma problemática pouco discutida pela comunidade acadêmica, nos grupos de estudos, nas salas de aula de nível superior e nos demais ambientes.

A pesquisa tem como propósito discutir e abordar os vários aspectos da política pública de ensino superior, como também questionar o projeto neoliberal e as novas configurações que surgiram em torno das políticas públicas, no qual nosso maior foco aqui será a política pública da educação.

No âmbito do presente estudo realizado, o método usado foi do tipo bibliográfico, a relevância do trabalho foi discutir e identificar a mercantilização do ensino superior privado e o projeto neoliberal, mostrando as novas configurações da politica de ensino, após o projeto neoliberal começar fazer novas construções. 
Id on Line Revista Multidisciplinar e de Psicolocia

Id on Line Multidisciplinary Journal and Psycology

\section{Aspectos históricos do neoliberalismo no Brasil}

Essa concepção do sistema capitalista que foi legitimada dentro da sociedade burguesa foi usada com as teorias vigentes da época para consolidar seu projeto hegemônico, econômico e conservador do sistema fundado pelo capitalismo. Este sistema consiste da exploração do trabalho excedente, da mais-valia que o trabalhador deixa para o dono dos meios de produção. Vale ressaltar que o sistema capitalista vive de crise, passa sempre por ciclos de crises estruturais no seu modelo de produção.

Segundo Boschetti (2009), são usadas várias formas para enfrentar e solucionar estas crises, como a forma de desenvolvimento do capitalismo, diversas formas de organização das classes sociais e de constituição e desenvolvimento do Estado a partir da historicidade, como também múltiplas maneiras de responder as crises.

Em outro momento a autora afirma que do ponto de vista da organização da economia e das relações sociais, "caracteriza-se como uma crise de superprodução, determinada pelo processo incessante de busca de superlucros e superacumulação". (p.66, 2010).

Nesta fala fica claro o projeto colocado em prática pelo capitalismo, o sistema dominante e conservador, que vem confirmando sua ideologia na sociedade, que é marcada por valores, regras, costumes e comportamentos estabelecidos pelos sujeitos que fazem parte dessa conjuntura do sistema capitalista, para manter a exploração universal e conservação da propriedade privada.

Ver-se que a partir dos anos de 1990, as novas transformações que ocorreram no mundo, com o modelo econômico brasileiro entra em crise, devido não atender mais ao sistema estrutural ao qual circulava pelo mundo, então foi adotada uma nova política estrutural para o país. O neoliberalismo implantado no Brasil que supostamente tende a colocar ordem e progresso o sistema financeiro do país. Claro que para o sistema financeiro aderir muito bem em partes e para a classe dos trabalhadores e os demais foi um fiasco.

Sabe-se que, o ajuste neoliberal implantado no Brasil, afetou a condição de vida da classe dos trabalhadores, as camadas mais pobres da população, sem qualquer atuação do Estado com políticas públicas voltadas para as camadas vulneráveis. Absorvendo assim investimentos para o capital, Mas ainda, a desregulamentação dos direitos trabalhistas e a 
flexibilização do trabalho, e a entrada da tecnologia acarretou um mar de desempregados e o desemprego estrutural.

Nessas últimas décadas, a sociedade contemporânea tem passado por fortes impactos em todos os âmbitos das relações sociais, inclusive as de caráter capitalista. "O neoliberalismo acirra a exploração da força de trabalho, mas não a institui; amplia as formas de "exploração", de "enriquecimento" e acumulação, por outro lado, é de empobrecimento" (DURIGUETTO; MONTAÑO, 2011, p.194).

Observa-se que com as transformações que vinha ocorrendo no mundo do trabalho, mais as medidas adotadas pelo Fundo Monetário Internacional, logo este quadro chegou ao Brasil com medidas de intervenção do neoliberalismo. O país encontrava-se numa situação muito delicada, então quando as medidas foram executadas a classe trabalhadora e os demais cidadãos compartilharam da crise. Um dos setores que foram bastante afetados foi à educação, inclusive o ensino superior.

Segundo Giannotti (1986) a educação, o ensino superior precisamente vive um paradoxo, precisa de outros conhecimentos, a própria conjuntura da sociedade moderna alimenta-se de novos conhecimentos e tecnologia para fazer uma construção avançada da exploração e mediante este contexto transforma o trabalho e molda o conhecimento ao seu favor.

\section{Nesse sentido Giannotti:}

[...] um contexto em que o conhecimento morto molda de forma segura o conhecimento vivo. Agora, quando o tempo histórico se torna rapidíssimo, quando os pormenores da vida cotidiana se transformam a cada instante, as inovações culturais sofrem do câncer duma rápida obsolescência; depressa a novidade mais retumbante mostra sua verdadeira face de velho personagem maquiado para o consumo [...] (1986, p. 21).

O autor na sua fala deixa clara a manobra que o capitalismo faz no ensino superior, usa do conhecimento para seu uso fruto e depois o transforma para adequar-se nas suas condições de manipulação e exploração. Tenta transformar o trabalho intelectual, numa atividade sem valor e num contexto que torna os condicionalizantes em simples mercadoria, para o consumo em sociedade, mascarado com os artifícios que o capitalismo sabe usar como ninguém. 
Id on Line Revista Multidisciplinar e de Psicoloqia

Id on Line Multidisciplinary Journal and Psycology

\section{O projeto neoliberal e a educação superior}

No Brasil teve uma reforma constitucional para inserir algumas medidas implementada para logo após serem aprovadas estas novas regras a serem cumpridas na carta constitucional, na condição de manobrar o sistema brasileiro aos modelos exigidos pelos padrões internacionais d Estado e economia, no qual tendem a ser formatar aos moldes do modelo neoliberal, como argumenta Mazzilli (2011, p. 215).

[...] Para os chamados neoliberais, a Constituição precisaria ser modificado para permitir a chamada internacionalização de nossa economia, como primeiro passo no sentido da diminuição do Estado: a privatização das grandes empresas estatais e um novo enfoque sobre o que se deve considerar, no domínio econômico, interesses nacionais. [...]

O modelo liberal já vinha agindo aqui por muito tempo, o detalhe que foi muito discreto, adotando as ideias liberais da Europa, num contexto econômico. O projeto liberal age aqui por meio das medidas adotadas na carta constituição. Como também nas próprias brechas deixadas nos textos constitucionais para futuramente serem adequados para legislação que seria colocada em prática.

Fazendo um breve resgate histórico para compreender como chegou a está crise no ensino superior privado e como o projeto neoliberal tem tomado de conta desse processo que se tornou muito rentável para o mercado privado. A classe trabalhadora hoje vivencia uma profunda crise da reestrutura produtiva e a precarização do trabalho, ainda nos formatos da crise de 1970. Nesse contexto ao qual o capitalismo opera temos este seguinte quadro.

Conforme Silva e Sguissardi:

[...] a expansão do capital na sociedade, em suas diversas atividades, produz uma tendência de saturação e uma consequente queda da taxa geral de lucros, obrigando o movimento de expansão a redirecionar-se para outros espaços nos quais a saturação ainda não se deu. Na mesma direção, estamos constatando um "tendencial esgotamento, ou pelo menos, o questionamento do modelo clássico taylorista/fordista de organização da produção, e a decorrente emergência de novos modelos" [...] (SILVA E SGUISSARDI, 2001, p. 102).

Na sociedade capitalista existe um processo no qual ele sempre está renovando-se a cada ciclo, neste processo há sempre novos direcionamentos para uma nova forma de exploração da 
Id on Line Revista Multidisciplinar e de Psicolocia

Id on Line Multidisciplinary Journal and Psycology

mais-valia e assim mediante novos meios para captar, outros lucros para o capitalismo. Diante desse processo da reestruturação produtiva e a precarização do trabalho na qual a classe trabalhadora vivencia, ocorrem novos modelos quem não atende o novo processo de produção e nem da economia.

Diante desse novo formato, o capitalismo coloca em prática o projeto neoliberal, que e implantado com medidas de redução para o Estado, agora o Estado vai ser restrito e mínimo, as políticas públicas ofertadas a classe trabalhadora vão ser redimensionadas, com um caráter focalista e seletivista para a população, características do modelo neoliberal.

\section{Mercantilização x Ensino Superior no Brasil}

O modelo neoliberal é um conjunto de ideias políticas e econômicas capitalistas que visam a retração do Estado, sem qualquer participação do Estado tanto nos setor privado, como no social. Nessa conjuntura o papel do neoliberalismo na educação vai ter um novo contexto, vai sair de um papel social para sociedade e agora vai adentrar com uma característica totalmente capitalista.

Uma das repercussões a crise da mercantilização é os direitos sociais, foi á perda essencial dos direitos com saúde, educação, previdência social entre outros, que vai passar agora a ser "serviços" que você pode comprar em qualquer departamento comercial. Antes de toda a crise do Estado, os direitos sociais tinham respaldo na sociedade, devido sua conquista pela classe trabalhadora, e todos tinha direito e acesso, devido ao processo de luta da classe trabalhadora para sua conquista, na qual resultaram direitos e deveres.

Com o projeto neoliberal difundido no Brasil a educação aqui vai passar por uma readaptação, com um viés de Estado mínimo sem financiamento, sem estímulos para pesquisa e extensão e uma evolução dos professores. Claro que desde a implantação o neoliberalismo no Brasil o ensino superior tem passado e passa ainda por uma mercantilização e reforma no ensino superior que atravessa décadas.

A transformação que vem ocorrendo no mundo do trabalho nos tempos atuais está afetando a todos na sociedade capitalista, principalmente os direitos sociais e trabalhistas na qual a classe trabalhadora conquistou com muita luta e reivindicações. Nesse aspecto os 
impactos sociais na educação, atingiram muito o ensino superior, que passa por forte vendaval da mercantilização do ensino, como também desmonte da política pública da educação.

Diante do quadro do setor educacional em questão, as ações neoliberais estão sendo implantadas no sentido de fazer com o setor de serviços não exclusivos do Estado, que seja propriedade do setor privado e que o Estado não precise ter responsabilidade com os demais.

Assim fala Chauí:

[...] desde seu surgimento (no século XIII europeu), a universidade sempre foi uma instituição social, isto é, uma ação social e uma prática social fundada no reconhecimento público de sua legitimidade e de suas atribuições, num princípio de diferenciação que lhe confere autonomia perante outras instituições sociais e estruturadas por ordenamentos, regras, normas e valores de reconhecimento e legitimidade internos a ela. A legitimidade da universidade moderna fundou-se na conquista da ideia de autonomia do saber em face da religião e do Estado [...] (2001, p. 184).

Decorre nesse processo neoliberal instalado no Brasil, um enfraquecimento dos modelos educacionais aqui existentes, que tentam configurar com a mercantilização do ensino superior dentro das universidades públicas, descaracterizando o ensino público de qualidade e fornecendo um ensino privado sem qualificação e capacitando para o exército industrial de reserva.

Para o neoliberalismo o conceito de educação e totalmente desvirtuado, em favor de seus princípios, é para feito da sua prática educacional que está voltada para o mercado, um conceito individualista e consumidor. Pra o sistema liberal o que importa e o papel do ser consumista dos alunos e dos pais que vai gerar uma rentabilidade que o mercado vai ter.

\section{Efeitos desse panorama da precarização do Ensino Superior na conjuntura atual}

Para Frigoto (1999), a educação superior nos últimos anos tem passado por fortes transformações, principalmente com a mão de ferro do projeto neoliberal. O setor privado de educação superior tem feito dessa modalidade uma nova forma de obter superlucros para o capital. Fazendo assim um comercio bem lucrativo chamado educação. 
[...] As mudanças decorrentes do novo padrão de acumulação do capitalismo, implantado nas sociedades globalizadas, que se refletem nos novos sistemas de produção e de comunicação, vêm imprimindo novas formas de trabalho que se refletem inclusive na educação superior. As reformas do Estado realizadas com o intuito de adequar o modelo econômico brasileiro ás normas e orientações das agências financeiras internacionais vêm operando profundas mudanças também sobre a educação superior no Brasil e, consequentemente, sobre o trabalho que ocorre no interior dessas instituições [...] (MAZZILLI, 2011, p. 216).

Dessa forma com o sistema capitalista soube usar á seu favor as transformações decorrentes com o processo de globalização que veio acontecer. Sendo assim a educação superior com as novas reformas acontecidas na sua estrutura teve que adequar-se ao padrão estabelecido. $\mathrm{O}$ ensino superior brasileiro tende agora obedecer ás normas e orientações das agências financeiras.

Para Miranda (2011) qual será o papel da educação como ferramenta de construção para resistência a ser exercida pelo proletariado, a função da educação superior numa dinâmica de transformação dessa alienação que a classe trabalhadora vivencia, como também a precarização existente nas instituições de ensino, como a total ausência do Estado.

[...] Indubiltavelmente, o papel da educação escolar se inscreve na apropriação de forma crítica do conhecimento historicamente produzido, para a construção de sujeitos críticos, capazes de superar a alienação que se impõe através de outros agentes educacionais cooptados pelo Estado, como a mídia escrita, falada e televisionada, além do importante espaço da internet [...] (MIRANDA apud ORSO; GONÇALVES e MATOS, 2011, p. 34 ).

Diante desse cenário percebemos a importância real da educação para o processo de conscientização da classe trabalhadora para a libertação da alienação, como forma de transformação do processo de exploração ao qual o sistema capitalista domina. Vale novamente repetir que e com a educação, vamos conseguir transformação a sociedade.

\section{Considerações Finais}

No decorrer da leitura pudemos perceber que o ensino advém de um processo longo, o qual, continua nas universidades. Nasce num contexto Europeu, e ao longo do tempo, foi disseminado pelo mundo. 
Id on Line Revista Multidisciplinar e de Psicolocia

Id on Line Multidisciplinary Journal and Psycology

A partir dos anos de 1970 uma crise profunda assola o sistema Europeu, e consequentemente outras economias de grande porte. Com a crise estabelecida, o sistema governamental adota um novo modelo para controlar a situação da economia. Com isso foi adotado o modelo liberal, e este novo modelo trouxe consigo as medidas neoliberais para a educação superior.

Trazendo a discussão para nossa realidade, o contexto antes era muito precário. Porém tínhamos universidades e ensino de alta qualidade apesar de todas as dificuldades. Com a reforma da educação, vem o atendimento às exigências das agências internacionais, as quais o novo modelo econômico estabelecia normas e regras.

Nesse sentido o ensino superior brasileiro, dotado de outro tipo de normatização, agora passa a ser gestado por entidades, instituições, faculdades privadas e outras representações, que adentram o Brasil com um modelo de ensino superior para uma população que não têm acesso. Coloca-se em oferta alternativa uma nova modalidade de ensino de outras experiências, o ensino semipresencial e a distância.

Com estas novas modalidades de ensino superior, e incentivadas pelo governo, vem o financiamento do capital privado, que tem assolado o país. Com polos situados nos quatro cantos do Brasil, tem ocorrido uma verdadeira mercantilização do ensino superior, de forma nem sempre legalizadas através do aval do Estado. O produto educação hoje é de mais fácil acesso, porém sem a garantia da qualidade do ensino ofertado.

O tripé ensino, pesquisa e extensão nem sempre tem sido oferecido aos estudantes, na forma como concebeu o Ministério da Educação no Brasil.

Portanto, é preciso que está realidade seja transformada, de forma que a sociedade possa usufruir dos conhecimentos gerados pelos pesquisadores.

A população não necessita apenas de um certificado de um nível superior, mais sim de liberdade de conhecimento, sair dessa alienação cultural a qual nos sujeitamos na medida em que não fazemos ciência nos moldes internacionais requeridos.

Precisamos refletir, construir, aprender para transformar está sociedade numa forma de organização coletiva, para acabar de vez está ideia da exploração do homem pelo homem. 
Id on Line Revista Multidisciplinar e de Psicolocia

Id on Line Multidisciplinary Journal and Psycology

\section{Referências}

CHAUÍ, M. Escritos sobre a universidade. São Paulo: UNESP, 2001.

FRIGOTO, G. Educação e formação humana: ajuste neoconservador e alternativa democrática. In: GENTILI, Pablo, SILVA, Tomaz Tadeu da (Orgs). $7^{\circ}$ ed. Neoliberalismo, qualidade total e educação: visões críticas. Petrópolis, RJ: Vozes 1999. p. 33-39.

GIANNOTTI, J. A. A universidade em ritmo de barbárie. São Paulo: Brasiliense, 1986.

MAZZILLI, S. Ensino, pesquisa e extensão: reconfiguração da universidade brasileira em tempos de redemocratização do Estado. RBPAE - v. 27, n. 2, p: 205-221, maio/ago. 2011.

MINAYO, C.S. (Organizadora). Pesquisa Social. 29 Ed. Petrópolis, RJ: Vozes, 2010.

ORSO, P. J; GONÇALVES, S. R; MATTOS, V. M (Org). Educação, Estado e Contradições Sociais. São Paulo: Outras Expressões, 2011.

SILVA JR., J. R., SGUISSARDI, V. Novas faces da educação superior no Brasil: reforma do estado e mudança na produção. $2^{\circ}$ ed. Ver. Bragança Paulista, SP: Cortez, 2001.

\section{Como citar este artigo (Formato ABNT):}

LIMA, A.A.; OLIVEIRA, R.T.P. A Mercantilização do Ensino Superior à partir do projeto neoliberal. Id on Line Revista Multidisciplinar e de Psicologia, Outubro de 2016, vol.10, n.31, p. 192-201. ISSN 1981-1179.

Recebido: 14/08/2016.

Aceito: 19/08/2016 